\title{
Establish Institutional Authority and Enhance the Effect of Education and Management for College Students
}

\author{
Tao Chen ${ }^{\mathrm{a}, *}$ and Wenchao $\mathrm{Lu}^{\mathrm{b}}$
}

School of Civil Engineering, Huang he Science \& Technology College, Zhengzhou, Henan, China

aemail: zzct1979@126.com, bemail: 2246298011@qq.com

${ }^{*}$ Corresponding author

Keywords: Institutional authority; college students; education and management; effect

\begin{abstract}
Ideological and moral education is an important content of the education and management of college students. Therein institutionalization is an important way to standardize the management of college students and enhance the actual effect of students' moral education. The establishment of institution authority has its sufficient necessity and possibility in practice, which needs to be realized through the efforts of three links. First, we should establish a scientific and rational system. Second, we should strengthen the implementation of the system. Third, we need to maintain the system.
\end{abstract}

\section{确立制度权威，增强高校学生教育管理工作实效}

\author{
陈涛 $a,{ }^{*}$ 卢文潮 ${ }^{b}$ \\ 黄河科技学院建筑工程学院, 郑州, 河南, 中国 \\ aemail: zzct1979@126.com, bemail: 2246298011@qq.com \\ 通讯作者
}

关键词: 制度权威; 高校学生; 教育管理; 实效

中文摘要: 思想道德教育是高校学生教育管理管理工作的一项重要内容, 其中制度化建设是规 范高校学生管理工作, 增强学生德育工作实效的重要途径, 是顺利实现培养社会主义事业合 格建设者和可靠接班人目标的有力保障。确立制度的权威性在实践中有其充分的必要性和可 能性, 需通过三个环节的努力得以实现: 第一, 要科学合理建制; 第二, 要加强制度的贯彻 执行力度; 第三，要运作制度维护机制。

\section{1. 引言}

随着法制观念日益深人人心，社会各单位对制度化建设的重视程度也日益加强，各类规 章制度的建立有力地推进了相关工作的科学化、规范化, 使各方权责有章可循、有制可依, 从而提高了生产、管理工作效率。但在实践过程中，还存在着制度设计不合理、贯彻执行不 力、不能与时俱进等问题 ${ }^{[1]}$ 。在高校学生教育管理工作中, 要提高高校学生管理工作水平进 而加强学生德育效果, 就必须克服相关管理制度中的这些弊端, 坚决确立制度的权威性。 


\section{2. 确立制度权威的必要性}

在《现代汉语词典》中，“权威”一词有两个义项：（1）“使人信服的力量和威望”; （2）“在某种范围内最有威望和地位的人和事物”。在实际应用中，权威指 “在相信他或她 施加影响的权力的合法性基础上要求别人服从的可能性” 。权威的功能基本体现在以下三个 方面：（1）使处于权威影响力范围内的主、从两方形成共同的意志; (2) 使这一范围内的 人们接受统一 的价值标准; (3) 为全体成员提供共同遵循的行为模式。

本文中要讨论的 “制度权威”，在上述意义的基础上更突出它的可依赖性（公平正义） 和感召性 (引导自律) , 不是建立剥夺个人自由的专制权威, 而是用权威清除障碍以保障个 人自由发展。这对正处于自主意识开始彰显时期的中国大学生而言尤其重要, 对其正确看待 约束、恰当处理张扬自我和服从秩序的关系，以及强化现代法制观念都很有益处。

\section{1 权威性是制度发挥规范作用的保障}

制度在狭义上是指一种人为制定的正式化、理性化、系统化和成文的行为规范，它在约 束人们行为的同时又为其提供可以自由活动的空间, 是协调自由与秩序关系的一种方式。自 由和秩序是相互联系的：自由是在一定秩序中的自由，而秩序存在的重要目的是保障自由; 自由有突破秩序之限制的倾向，秩序也有限制自由的倾向。换句话说，制度是一种为了一 定目的而实施的控制措施, 以使活动对象向着特定的方向发展, 使自由和秩序在统一体中均 达到最大化实现 [2]。在这个过程中, 制度必须具备权威性、才能起到它 “行为规范” 的作用, 表现为 “关系人员背难认可” 和 “违规者必受惩罚” ，从而使集体秩序得以维持，并使事先 约定的个体合理权益得到保证。很容易理解, 没有权威的 “制度” , 其实是废纸一张, 不管 形式上多么正式、多么理性和多么系统。

在高校的学生教育管理制度中, 由于很多制度在学生中的知晓度、认可度较低和执行中 处罚兄现的随意性较大, 因此缺乏真正权威, 有的只是不合时宜的因害怕 “被惩罚威胁” 而 形成的强制性权威; 更有甚者, 学生管理部门为了应付检在评估而草率出台 “制度汇编” , 这种文件般没有多大可行性，这些没有权威性保障的制度当然不能发挥它应有的规范作用。

\section{2 提高工作科学性、有效性依赖于制度权威}

制度一般是在经验积累和政策指导的基础上设计与确立的，一旦实施，就应该成为工作 开展的原则与标准。这样, 在制度的应用中就可以有效防止个人决策或政策意见解释表达的 随意性，从而提高工作的严谨性和科学性。而让这种 “应然” 转变为 “实然” 的力量正是制 度权威 ${ }^{[3]}$ 。

由于中国社会的教育习惯，在高校中“人治”现象较为普遍，无论是老师还是学生，似 乎都习惯了 “言传身教” : 老师喜欢展现自己的学术自由与教育个性, 学生喜欢依据老师个人 的管理要求规范自己的行为。这样做本身没有什么问题, 关键是要在制度搭建的框架内和平 台上进行。还有一种现象是由于权威性的缺乏而直接导致对制度的不信任: 我们在日常工作中 经常会遇到学生来询问一些事情, 而相关信息早已明文公示, 还有学生会把 “xx说的” 作为 支撑自己行为和逃避责任的依据, 而这个 “ $\mathrm{xx}$ ” 并非权威人士, 好像从一个他人口中说出的 话要比规章制度中的文字更可靠。这样往往会由于行为指南的不一致和不准确造成具体工作 失误、学生利益受损, 而易使学生迁怒于学校, 影响长期的校园管理秩序。这种现象折射出 的是学校制度权威性的贵乏。

另外, 将工作传统、习惯和成功经验加以制度化并成文记录, 还可以保障工作的延续性, 不至于因工作人员的调离而把工作方法、成果和经验等 “全部带走” ，而使新的人员到新的 岗位面临一个名副其实的新的开始; 即使在前后辈间 “口口相传、手把手教” 的传帮带过程 中, 也要有规章来弥补它显而易见的缺陷——相对随意和整体低效。总之, 避免在不必要的 
简单重复工作中浪费相关资源或不能在效能指标内充分利用资源, 就需要制度权威来规范和 调节，从而也就保持或提高了工作效率。

还有相关调查研究表明, 目前高校师生对学生的管理制度, 尤其是在和学生利益直接相 关的学生奖惩制度的态度上存在着较大分歧, 老师肯定多些, 学生否定多一些 ${ }^{[4]}$ 。这种缺乏 统一权威认同的局面在教育上会产生施教的脱节, 在管理上会产生事实上的无效。而且从整 体上看, 高校中的学生德育与智育过程, 相对于中小学时期存在着事实上的分离, 即学生思 想道德和专业知识均由专门的人员负责传授提高。没有制度去设定一个参照系的话, 学生行 为的好坏与教师个人的严厉程度挂钩的现象还会延续, 而学生自由个性的张扬和自主意识的 增强必然使这种矛盾激化。这样的话必须由制度来保证实高校各类教育人员对学生教育口径 的一致, 从而有助于获得相对致的制度权威认同, 以此来提高学生德育管理工作的效率。

\section{3 制度权威是主客体关系和谐的有效途径}

没有规矩，不成方圆。制度权威的真正彰显，就是为了保证同样的情形在不同人的身上 能够得到同样的对待, 这在保护相对弱势群体时尤其重要。先期订立一个公认的和约(制度), 规定履约就能得到相应的利益, 违约就得承担相应的责任。这样在一种秩序框架内, “人一 人” 的直接冲突会因 “人一制度一人” 的关系模式而有效避免, 人与人的关系就会在公 认的游戏规则内得到改善, 从此衍生出的各种权利与义务的主客体关系也就最终走向和谐。

高校对学生进行德育来规范其行为, 一般通过辅导员、班主任等专兼职的学工干部落实, 而很多高校还达不到教育部《关于加强高等学校辅导员班主任队伍建设的意见》中 “专职辅 导员总体上按 1 : 200的比例配备” 的要求, 学生数量较多、日常工作量较大, 加之与学生直 接接触的工作性质要求, 使学工干部在日常管理过程中难免与学生出现各种各样的利益冲突, 而且很多情况下是隐性的, “没有反对的声音, 并不代表没有反对的思想” , 从而成为校园 稳定和谐的隐患。如果有相对完善且真正有权威的管理制度休系, 对师生行为都有合理的规 范要求, 必定会减轻常务负担, 而使学工干部把精力放在主要、重点之处, 不断学习创新、 改进工作方法, 有利于增强德育工作实效, 提高学生品德素质, 营造稳定和谐的校园环境。

\section{3 确立制度权威的环节}

\section{1 科学、合理建制}

\section{1 .1 按民主集中的程序进行制度设定}

西方现代管理理论之社会系统学派的创始人切斯特・巴纳德认为: 命令是否有权威决定 于接受命令的人，而不是决定于权威者或发布命令的人 ${ }^{[5]}$ 。同样，一项制度的权威不应也不 能由制定者的意志和制度外的力量来保证, 而只能由被规范群体来确立, 即本文开篇所提到 的 “可依赖性” 和 “感召性”。

所以, 制度的设计一定要走调查研究、民主集中的过程: (1) 搜集建制是否必要、规范 程度应如何等基础信息; （2）召开听证会, 利益代表展开对话, 达成妥协; （3）根据制度 目标集中相关民意, 体现在相关条文中; （4）明文规定特殊情形下的例外情形和应急程序, 以防止教条主义而又不损害制度公平。

大学管理教育的核心内容之一是责任教育, 一指大学承担着为社会输送德才兼备建设者 的责任, 二指培养大学生对自己行为负责并承担社会责任的意识。“这是为你好” 可能是学 生从小到大听到的频率最高、虽反感但又无可奈何的一句话, 其反映出了学校、家庭等管理 监护主体的良苦用心和育人的责任感, 但往往忽略了学生的意见表达, 忽视了学生的主动性 和自我管理, 这种一厢情息, 并不能让学生确实感到获益。同样, 高校在制定管理制度时容 易从校方利益和承担的社会责任出发, 即使考虑学生的利益也相当多是想当然的, 缺乏必要 的征询和沟通, 因而在实施过程中会受到学生不同程度的抵触。 
“代沟” 的出现既可以理解为 “年轻一代的反叛” ，也可以理解为 “年长一代的落伍”， 逾越的正确方式只有对话。参与学校管理与建设正是展开对话, 培养大学生责任意识的有效 方式, 若能参与制定关乎自身利益的游戏规则, 学生的热情和积极性冊庸置疑, 毕竟首先要 学会对自己负责, 才能对社会尽责。所以, 高校建章立制时, 不仅要体现管理者的意志, 也 要广泛听取来自各方面的意见, 尤其是服务对象一一学生的声音。那么, 制度权威的确立自 然会水到渠成。

遵循民主集中的原则, 才能保证制度的科学性, 才能体现以人为本。有群众意见基础才 能有规范作用, 才能有针对性, 才能把导向意图贯穿其中, 保证制度体系的系统性, 这样也 才有权威。

\section{1 .2 按照严谨的格式及措辞来制定制度}

民主集中的成果要通过语言文字表达出来, 形成正式的制度文本。现在的制度制定过程 中不少存在着很大的随意性, 尤其在较小范围和较低级别的制度设计单位, 口头用语、错别 字、不统一的段落格式、言辞不准确、易产生歧义等情况无疑降低了制度的权威性。制度是 一个严肃的文本形式, 要遵守起码的写作要求, 行文格式要反映出制度制定者的态度, 会直 接影响公众评价和执行效果。所以, 制度要注意用语简洁, 严谨, 使用文字和标点符号要规 范、准确, 条文内容要明确、具体。

值得注意的是，在高校这种文化高层次聚集的地方，还经常出现行文粗粘、别字连篇、 言语自相矛盾的制度文件，这在公众看来是对 “没有说服力” 的最佳说服力，不加克服，制 度的权威就难以确立。

\section{2 加大制度的执行力度}

制度不用于实施, 就失去了它存在的意义, 更无权威可言。大力贯彻执行, 是体现制度 权威性的中心环节，是防止 “上墙制度” 和 “死制度” 产生的最有效方法。

\subsection{1 制度要适度宣传}

讲到贯彻执行制度，首先要将其公布于众，使人知晓，然后接受，然后奉为权威。否则 一旦违规，“不知者无罪” 或 “不知者亦有罪” 的处理意见都难以使人信服，制度权威性必 受损害。为了让该知道的人知道, 通过必要途径对制度本身及意义展开适度宣传, 有助于减 少制度执行的阻力。这是一个长期的工作，不同阶段应有不同的重点。

而有些高校在制定和执行学生管理规章时缺乏公开性, 使得受处理的学生都不清楚校方 做出决定的依据, 而只是被动接受处理结果, 这显然侵犯了学生的知情权和申辩权, 制度也 就无真正的权威可言。

\subsection{2 严格执行程序}

必须严格执行程序，才能发挥制度的规范作用。按制度约定的套路出牌，才能做到 “有 制必依, 履制必严, 违制必究”, 才能确立制度权威。尽管程序不能全部保证结果与预期的 符合，但若没有程序，制度也只能是 “空中楼阁”。

高校在对学生违规处罚时一般都认同 “惩前皆后、治病教人” 的原则, 常说要以教育引 导为主、处罚为辅, 但在具体操作时会出现两种片面情形：一是 “以教代罚”, 说说了事, 违规地减轻或取消应予的处罚; 二是 “以罚代教” ，不问青红皇白、不做说服教育，仅仅 “为 罚而罚”。这两种工作方式都不能起到良好的教育效果, 前者不能让学生懂得错误行为是要 付出代价的, 后者也不能让学生真正心服口服。教育、尤其是德育工作的特殊性, 要求管理 者在履行制度时首先必须要对学生进行晓之以理、动之以情的教育引导, 在就事论理中让他 们深刻明白是非曲直, 帮助他们做出正确的对错判断; 其次, 必须要追究违反制度学生的责 任, 严格执行相关规定, 培养他们尊重规则的品德素质, 促其形成对自身行为负责的意识。 双管齐下才能预防学生重蹈覆辙, 制度权威就会在这样的程序过程中逐渐确立。 
还有, 充分发挥大学生的主观能动、自我管理作用, 让学生特别是学生党员、干部等优 秀学生参与德育工作, 可以大大减轻学工干部工作负担并提高学生的综合素质。但在实践中, 这种学生参与校方管理行为的可靠性和有效性, 必须由相应的制度来保证, 重点在规范学生 开展工作的程序。

\subsection{3 排除 “特权”}

在制度规定的权利和义务关系范围内的主客体，只享受权利而不承担义务的情形，就称 之为 “特权”。除在制度设计时公认的免责状况外, 有两种特权要求是要坚决排除的:一是来 自规范内 “只许州官放火, 不许百姓点灯” 的凌驾行为; 二是规范外权势领导的个人意志干 预。制度权威是要保护相同个体的公平自由权利, 两种人为的特权要求干涉制度的贯彻执行, 都会破坏制度的公正性并降低其可信度，从而动摇制度权威，加速制度消亡。

高校现在已经不是与世隔绝的象牙塔了，可以说完全融入了社会关系网中。在校学生间 普遍存在着家庭经济状况、父母权势、社会背景等方面的较大差距, 很多歪风邪气也影响着 学生的价值观念, 违反规章制度后, 经常会有校内外的力量来干预, 会造成基层学工干部的 工作困难和损害制度的公平性, 更为严重的是威胁国家教育制度本身。鉴于其对学生、社会 的消极影响, 在高校中排除 “特权” 应该引起社会各界的重视, 确实是一项非常重要的工作。

\section{3 建立制度维护机制}

制度一旦建立, 就要保持相对的稳定性, 不能 “三天打鱼, 两天晒网”，但也并不是一 成不变的, 要有适度的修订, 以延续其生命力。这就要建立制度的运行维护机制。虽然制度 设计的谨慎, 要求制定者有非常理性的前瞻, 但实践情况是不断变化的, 难免有条文疏漏之 处, 这就要及时地解释、修改、补充相关内容; 当制度存在的基础性条件丧失的时候, 就要 将其废除, 建立新的制度取而代之, 以做到与时俱进。不同群体的制度规范要有相应的维护 机制, 规定维护人员、维护频率、维护方式等内容, 使其能够保证制度健康。这样, 制度才 能成为关系人始终信赖的行为规则, 才能确立并体现权威 ${ }^{[6]}$ 。

其实, 制度的消亡是必然的, 因为制度权威的真正确立是由他律深化为自律。随着文明 的演进, 当那些秩序规则内化为人的素质时, 它的使命就完结了, 制度在狭义上就消亡了。 增强高校学生德育工作实效, 就是要提高学生将他律深化为自律的 “转化率” , 维护德育管 理制度其实就是维护学生成长的一片温床。

\section{4. 结束语}

制度权威不应该仅仅被理解为 “制度的权威性”，而它就是制度的精髓本质，确立制度 权威就像把一根结实的线握在了手中, 可以在线绳限定的空间内自由放飞个体意志, 有助于 实现 “无为而治”, 使人能够全身心地投人到工作生活中, 实现各自的价值, 实现和谐社会的 目标，最终实现人类的理想。

高校需要制度权威下的管理, 学生德育实效需要科学程序的保障。高校对大学生进行道 德教育并不是要压抑人的主体性, 而是要为大学生自由而全面的发展提供深厚而持久的道德 动力和道德关怀。高校对大学生进行按照权威制度依法管理也不是将大学生置于高校育人的 对立面, 而是要创设公平、正义的良好机制和环境, 保障每个大学生能平等地获得自由而全 面发展的机会。高校育人不能把手段当作目标, 否则就会造成教育的 “异化”。只有在权威制 度框架内, 对大学生教育和管理既动之以情、晓之以理, 又制之有衡、行之有度, 那么学生 才会明白学校、管理者的良苦用心，教育和管理的实效也才会得到有效提升 ${ }^{[7]}$ 。

\section{References}

[1] Songyu Li, Institutional Authority and Personal Authority, Journal of Shandong Teachers' University(Social Science Edition), vol.3, pp. 121-124, 2004. 
[2] Jiang Peng, "freedom and order" are the mainline of modern university system, Journal of Hebei Normal University (education science edition), vol.7, pp. 62-62, 2005.

[3] Minggu Lai, Hesheng Liu, University governance: from institutional dimension to cultural dimension, Modern University Education, vol.7, pp. 90-93, 2005.

[4] Yifan Cai, Yuko Aoyama, Fragmented authorities, institutional misalignments, and challenges to renewable energy transition: A case study of wind power curtailment in China , Energy Research \& Social Science, pp.71-79,2018(4).

[5] Margaret - Meade, Translated by Zhou Yi. Research on generation gap between culture and commitment. Shi jia zhuang: Hebei People's Publishing House, 1987.

[6] Tongshun Cheng, Xijing Xing, Legitimacy, Identification and Power:The logic of Institutional Authority Construction, The Journal of Shanghai Administration Institute, pp. 12-18,2016(5).

[7] Yong Liu, Exploration on Relationship between Moral Education and Legal Education in College Students' Ideological Education, Vocational Education Research in Xinjiang, pp. 77-79, 2018(1). 